\title{
Practices and Discourses of Academics: Local Lessons to Address the Digital Shift in Academic Management
}

\author{
Carla Fardella \\ fardellacarla@hotmail.com \\ Universidad Andrés Bello, Chile \\ Centro Núcleo Milenio Autoridad y Asimetrías de Poder \\ Enrique Baleriola \\ enrique.baleriola@pucv.cl \\ Pontificia Universidad Católica de Valparaíso, Chile \\ Centro de Investigación para la Educación Inclusiva \\ Giazú Enciso \\ gencisodominguez@jjay.cuny.edu \\ City University of New York, United States \\ Critical Interdisciplinary Studies Research Group
}

\begin{abstract}
Since the 1980s, accountability, performance measurement and competitiveness have been implemented in universities globally. It is the management logic known as New Public Management (NPM). But the NPM in contemporary academia is not understood without attending to the emergence of digital management devices and platforms (DMDs). It is the combination of both events that we have called the digital turn in university management. The implementation of DMDs is not a homogeneous and fully satisfactory process but is loaded with attempts, fails, and failures that need the voice of academics to be understood in its extension. This article presents the results of 40 interviews with academics about their experience and engagement with DMDs. The results point to the existence of at least three repertoires: 1) device-lover, 2) functionalpragmatic and 3) oppositionist-rejector. Together, these results point out that, on one hand, both the experience and the identity of the academic; and on the other hand, the relationship with the institutional context; both are the key to the successful implementation of the DMDs.
\end{abstract}

\section{Keywords:}

Discourse analysis, Higher Education, Academic Management, Accountability, Digital devices. 


\section{Introduction}

Guided by the New Public Management (NPM) model, universities, on a global and national scale, have developed profound changes in their administration during the last decades (Anderson, 2008; Hall, Gunter, and Serpieri, 2015; Gill, 2009; Slaughter \& Leslie, 1997; 2001). The NPM is a management model for organizations and public services that seeks to transfer the logic of the private world, supported by arguments of efficiency and integrity. Although its implementation is diverse, it coincides in seeking the privatization of public services, promoting competition between organizations that offer the same service, evaluating and monitoring services through accountability systems, and the implementation of a series of incentives and punishments based on the accomplishment of the goals.

The reorganization of Chilean higher education is part of this logic, prioritizing management over other institutional processes (Bernasconi, 2015). Thus, management in higher education today must face a new relationship with the State and address demands such as the diversification of its sources of financing; deal with the market as the main regulatory mechanism and install a culture of accountability among its members. Indeed, the successful adaptation of the university to the new times is associated, among other things, with its main workforce: academics (Brunner, 2008; OECD, 2009). Thus, the standardized evaluation of teaching work, productivity rankings, performance indicators, bonuses for meeting goals or the competitiveness of different funds to carry out work activities, have spread with surprising naturalness.

In this scenario, universities have innovated in increasingly sophisticated management devices to lead, register and monitor the academic workforce, aligning it with the current demands of higher education. Without a doubt, these actions are only possible under the sophisticated development of management instruments necessarily coupled with the accelerated and increasing use of digital tools (Gill, 2009, United Nations, 2019, Slaughter and Leslie, 1997; 2001). Certainly, the current strength of university management cannot be understood without attending to the digital turn of academic management that requires online accountability (Vanderlinde, Ban Braak and Tondeur, 2010): check-in check-out controls, time control processes, monitoring the amount of time spending on internet, intranet, social network, general activity during your work day, or other platforms are some examples of this. This digital turn would not simply consist of digitizing the teaching-learning processes but would go to the root of the management model behind the academic work processes (Henderson, Selwyn, Finger and Aston, 2015).

Therefore, since the $80 \mathrm{~s}$, research in higher education begins to explore the digital turn, suggesting that if institutions wish to remain competitive, the key is in the successful incorporation of technology for all its processes: teaching and learning practices, managing their resources, links with the environment (Kinzie, Delcourt, and Powers, 1994; Tynan, Ryan, Hinton and Lamont Mills, 2012; Selwyn, 2014). Although the importance of Digital Management Devices (DMDs) is not questioned, obviously the digital turn in university management has had a different degree of acceptance by academics (Gill, 2009; Moore and Robinson, 2015; Selwyn, 2007). And while many academics are resistant, others use them to improve their work capacity (Selwyn, Nemorin \& Johnson, 2016; Castañeda \& Selwyn, 2018). This assumes that at the micro-level, the success or failure of its implementation has been more controversial than expected and its implications have often been underestimated. For this reason, the objective of this article is to characterize the response of academics to the digital turn in the management of higher education. If the success of the transformations in higher education depends on the adherence of its workforce to the changes, it is a priority to know its discourses, practices, and controversies. 


\section{The digital turn of university management strategies: Tensions and contradictions in academic work}

Chile has been considered on multiple occasions as the global laboratory for New Public Management, and in particular, for accountability management processes (Thomas and Davies, 2005; Wittmann, 2008). Since the enactment in 1980, the Chilean State has adopted a subsidiary role in the provision of public services, abandoning the role of guarantor of the right to education (Brunner, 2008). With the recovery of democracy, this model is expanded and perfected based on the recommendations issued by different international organizations such as the World Bank or the Organization for Economic Cooperation and Development (World Bank, 2005, 2011; OECD, 2002, 2004 ). In this way, the New Public Management model ends up establishing itself as a primary way of understanding public services and to guide their optimal operation. In higher education services, this means 1) seeking private financing, 2) introducing competition between public and private universities to capture enrollment, under the premise that competition improves the quality and efficiency in the use of resources, 3) the implementation of standardized tests to measure and compare the quality between institutions (Bernasconi, 2015).

Thus, management is understood as a centerpiece of university quality. And although there are nuances about management, it has become the protagonist in each institution, the truth is that most universities converge in organizing their processes along classic lines of management: organization structure, systems of government and decision-making, the leadership of personnel, planning, execution and control of resources, monitoring, collection of information, etc. (Bernasconi, 2015). Currently, none of the processes indicated can be developed without the digital turnaround that management tools have given. Most of the monitoring and control processes are based on software and platforms; access to information, as well as the digital presence in decision-making spaces, is implicitly regulated by authorized passwords and accesses. The evaluation, as well as the monitoring of the achievement of goals of the academic staff, is unfailingly designed and determined by the use of these platforms. Similarly, the management of information and knowledge is a key area in the strategic direction of the institutions and it is not possible to imagine it before the digitization of the university (Chanphirun and Van Der Sijde, 2014). Several studies (Chesley, 2014; Gill, 2009; Richtel, 2011; Thompson, 2011) suggest that the incorporation of DMDs-based management practices is prevalent and global and would inevitably be altering working conditions, places, and relationships at work, and even the very notion of work.

A recurring theme in the literature reviewed is the relationship between the digital turn of management and the pace of work. The use of DMD would act by modifying the "temporal rhythms" of work experience. In this regard, Southerton (2007) points out that work culture has been installed where workers are expected to respond instantly to emails, punishing the delay in the response and rewarding speed.

This acceleration of work rhythms is associated with the intensification of academic work (Gill, 2009; Chesley, 2014). Intensification refers to how DMDs allow you to do more tasks in less time, but not only refers to the quantity but also the diversification of the tasks. And in this sense, management devices via self-tracking at work (Moore \& Robinson, 2015), promote the need not only to do the traditional tasks of an academic but also to monitor and self-conduct their behavior towards institutional goals. Although this has facilitated management processes, displacing accountability processes in workers and promoting self-regulatory behaviors, at the same time it is associated with conditions of self-exploitation and a chronic state of debt and default (Gill, 2009; Han, 2014). 
A third contradictory aspect is the so-called extensification of academic work (Chesley, 2014; Gill, 2009), understood as an overflow of the traditional limits of the academic workspace towards non-work spaces such as home or weekend time. Although extensification is perceived as the possibility of choice of the workplace by the academic, some studies also indicate that this allows higher levels of interruptions (Chesley, 2014) and accumulation of unforeseen events. This is related to both the perception of achievement of planned achievements and control over one's work (Moore and Robinson, 2015). Thus, the search for higher performance with the consequent evidence to perform (wirte a paper, attendance certificate or blog entry), makes it difficult to disconnect from academic obligations, which is known as living permanently in a state of always-on (Chesley, 2014: 59).

In summary, the complexity of the implementation of DMDs is evident in that, on the one hand, it has been found that the use of these devices has different advantages such as communication efficiency and greater accessibility, as well as enabling a wide range of styles. homework. But, on the other hand, the findings suggest that the use of DMDs also has negative implications for workers as it nurtures chronic sources of stress and distress (Chesley, 2014; Gill, 2009; Moore and Robinson, 2015). The literature is evident in its paradoxical tendencies that potentially provide advantages and disadvantages simultaneously and persistently over time, which is linked to processes of exhaustion and work commitment (Claartje, Zoonen and Fonner, 2016).

These tensions about DMDs in the academy are therefore an overt contradiction. According to Wajcman and Rose (2011), DMDs and their impact on users cannot be read outside the context in which it operates. As Castañeda and Selwyn (2018) point out, the meaning DMDs have and their implementation, do not operate in isolation from the environment, rather they are intertwined with previous cultures, norms and subjective aspects, often invisible. This is how DMDs can be inserted into the institution optimizing management practices, but also reconfiguring those that already exist, with implications not always foreseen for the university. This requires a careful analysis of DMDs. For all this, DMDs and their implementation cannot be analyzed separately, both from the meanings they have for academics and from the social interactions that support their use (Wajcman and Rose, 2011).

Thus, this work focuses on the diverse, contradictory and dilemmatic discourses of academics when characterizing the digital turn in the management of higher education.

\section{Methodology}

The findings we present are part of a qualitative approach study (Denzin and Lincoln, 1994). The design of this study included 40 interviews with Chilean academics from different disciplines and universities (private and public). The active interview was chosen as a collector method, a data production strategy whose distinctive quality is the fluid and flexible interaction between interviewers and interviewees, making it possible to cover the unique experiences of each participant (Holstein and Gubrium, 1995).

\begin{tabular}{|l|l|l|l|}
\hline $\begin{array}{l}\text { Paticipant } \\
\text { number }\end{array}$ & Discipline & Gender & $\begin{array}{l}\text { Type of } \\
\text { University }\end{array}$ \\
\hline 1 & Architecture & Man & Public \\
\hline 2 & Architecture & Woman & Public \\
\hline 3 & Biology & Man & Private \\
\hline
\end{tabular}




\begin{tabular}{|c|c|c|c|}
\hline 4 & Biology & Woman & Private \\
\hline 5 & Chemistry & Man & Public \\
\hline 6 & Chemistry & Woman & Private \\
\hline 7 & Design & Man & Private \\
\hline 8 & Engineering & Man & Private \\
\hline 9 & Engineering & Man & Public \\
\hline 10 & Engineering & Woman & Private \\
\hline 11 & Engineering & Woman & Public \\
\hline 12 & Engineering & Woman & Public \\
\hline 13 & Kinesioloy & Man & Private \\
\hline 14 & Law & Man & Private \\
\hline 15 & Law & Woman & Private \\
\hline 16 & Literature & Man & Public \\
\hline 17 & Literature & Woman & Public \\
\hline 18 & Management & Man & Public \\
\hline 19 & Management & Woman & Private \\
\hline 20 & Management & Woman & Public \\
\hline 21 & Medicine & Man & Public \\
\hline 22 & Medicine & Woman & Public \\
\hline 23 & Nursing & Woman & Public \\
\hline 24 & $\begin{array}{l}\text { Occupational } \\
\text { Therapist }\end{array}$ & Man & Public \\
\hline 25 & $\begin{array}{l}\text { Occupational } \\
\text { Therapist }\end{array}$ & Woman & Public \\
\hline 26 & Odontology & Man & Private \\
\hline 27 & Odontology & Woman & Private \\
\hline 28 & Pedagogy & Man & Private \\
\hline 29 & Pedagogy & Man & Private \\
\hline 30 & Pedagogy & Woman & Private \\
\hline 31 & Pedagogy & Woman & Private \\
\hline 32 & Physics & Man & Public \\
\hline 33 & Psychology & Man & Public \\
\hline 34 & Psychology & Man & Public \\
\hline 35 & Psychology & Woman & Private \\
\hline 36 & Social Work & Man & Private \\
\hline 37 & Social Work & Woman & Private \\
\hline 38 & Sociology & Man & Private \\
\hline 39 & Sociology & Woman & Public \\
\hline 40 & Sociology & Woman & Public \\
\hline
\end{tabular}

Table 1. Sample characteristics of the participants.

Source: Compiled by authors. 
From a discursive analysis perspective of the transcribed material, we sought to know the different practices and interpretive repertoires of academics about the digital turn in the management of higher education (Potter and Wetherell, 1987). The analysis model adopted studies people's accounts of their work and the description they make of it. We also study the evaluations and attributions that underlie the academic's accounts, rather than treating the data as "true" and neutral descriptions of the academic's work environment (Edwards and Potter, 1992; Potter and Wetherell, 1987).

The analysis of interpretive repertoires responds to a type of discourse analysis, where the central unit of study is the repertoires. The repertoire is understood as a discursive compilation that is constructed through the interaction of the speakers of a particular community. The repertoires are made up heterogeneously of a series of arguments, assumptions, metaphors, figures of speech and images. They are regular ways of interpreting the world, and at the same time that they guide the action of the subjects and make them intelligible to themselves and their community.

For this reason, interpretive repertoires are also understood as acts of positioning the subject against events or phenomena, since how we construct stories about a phenomenon always reveals the position from which it is spoken. Associated with this, the stories are always hybrid and above all dilemmatic, because even when they seek coherence, they are at the same time inconsistent, fragmented and contradictory (Billig et al., 1988). However, individual inconsistencies make sense by becoming regularities on a collective level. That's when we talk about interpretive repertoires, which is, relatively consistent linguistic compilations, which are activated according to the context, compared to certain ones (Van Der Merwe and Wetherell, 2019). In our case, the focus is on finding and analyzing the different interpretative positions (repertoires) around the digital turn in the management of higher education.

Finally, according to the ethical criteria of the National Commission for Scientific and Technological Research (CONICYT), the forty interviews had their respective informed consents and authorizations to be carried out. Furthermore, all personal or sensitive data was anonymized and/or replaced by other names that made the subjects and/or institutions unidentifiable.

\section{Results}

We present three interpretive repertoires: 1) Device-lover, 2) Functional-Pragmatic and 3) opposition-rejection. In order to clarify each one, we navigate through three different elements: first we present a description of its management tools, then the Faculty's position and at the end Faculty's actions around the digital turn in the management of higher education. It is through the development of these three elements that we constitute the corpus of each of the three repertoires. It is important to note that all participants used all three repertoires at different points in the interview, and there are no appreciable differences between discipline or university.

\section{a. Repertoire 1: Device-Lover}

We have named the first repertoire device-lover and it brings together stories and actions that positively value the digital turn of academic work, explicitly adhering to its use. This repertoire discursive constructs the digital turn in the management of academic work as a fundamental 
change in their daily work, showing conviction and motivation in the implementation and use of digital tools.

It should be noted that this repertoire is activated from specific digital tools. Among those named are: institutional and personal email, Google Scholar, WhatsApp, Indexes derived from it, ORCID, Kahoot. That is to say, a Faculty will identify as a device-lover only in front of specific digital tools and not to the digital turn of management itself.

Below, we present an illustrative fragment:

A: I work 87 hours, I have reached 117 in a few weeks.

B: And what do you think happens to someone who works that many hours?

A: Well, one can't have another life, to start with. So for me, it is very practical that my partner lives in Concepción and that it is the phone that communicates me. Many times I am working and I am talking over the phone while I am doing something that requires little attention, such as checking emails and being able to select which emails I have to answer or not. So I'm doing both, I'm not reading the emails, but I'm reading headers, etc. (Engineering)

This fragment shows how the device is valued when the benefit of its use is personal (not necessarily institutional). As evidence, the value lies in its potential to facilitate work and integrate harmoniously with other aspects of non-working life. Paradoxically, from the use of the device, not only academic work but also family relationships are reorganized.

Under this repertoire, another positive evaluation criterion has to do with the potential of the instruments to make academic work visible:

Whenever I publish an article or achieve something, I post it on Google Scholar and my ORCID profile. And sometimes, not always ... I check in Scopus or Publons if it appears and has been updated. I think it is important and in many calls (especially international ones) the application already asks you for the $H$ indexes or your citation index. And I must admit that I like to see the graphics and those bars that indicate your production each year ... or the number of citations ... at the end, it is how one knows if this year one has worked well or not. (Psychology)

In this excerpt, it demonstrates how digital accountability tools are perceived beyond their ability to monitor performance but are resignified and read by academics as an opportunity to display their work, maintain a digital identity based on the personal merits, visibility, and international impact, as well as following up on their work (Fardella, Corvalán and Zavala, 2019). In this way, the device-lover repertoire appropriates digital technologies individually in meritocratic terms.Efectivamente, las retóricas positivas hacia el uso de las tecnologías están transversalmente marcadas por la conveniencia individual que supone el uso de estos dispositivos (Castañeda y Selwin, 2018).

For me it is comfortable, I use it because it is easier. My courses and assignments are very well organized. So I don't spend as much time on that anymore. I use attendance applications or adapt some like Kahoot, which is an online game, I see how many students are connected if 
there are 30 and I have 30 students, then, I know the attendance. (Architecture)

Framed in the device-lovers repertoire, positive assessment is associated with actions in favor of device use, which triggers a vicious circle. The assessment is based on optimal use, even on the overuse of the tool. For example, most of the academics stated that they can continue working from home or when they are traveling (work or personal time) thanks to digital devices. Likewise, users invent ways to integrate the digital tools of the productive world into other spheres of their life.

We proposed to the students as a final project to build an audiovisual capsule to explain a specific concept. We got very good and creative projects that helped me show my friends and family what we do at university. (Psychology)

From this framework of device-lover, the use of devices is narrated with conviction, under the rhetoric of enthusiasm, speaking highly of the devices in front of colleagues and promoting their use within the department.

In this sense, as argued by Romero, Riquelme, and Halal (2019), the discourses of support of the use of these devices are based on the expectation about the results obtained with their use or the facilitating conditions they provide. Indeed, the assessment seems to come from whether or not it fits in with personal inclinations and styles, rather than with institutional duties.

A final aspect to highlight is that, although the devices that activate the repertoire are positively evaluated, none of those named in this category are from the official administration. This is interesting since in this repertoire the academic emphasizes relating directly to the device. Although Faculty is who controls the use of the tool, the assessment made by academics is at the individual level and not the institutional one.

3) oppositionist

\section{b. Repertoire 2: Functional-Pragmatic}

We have called the second repertoire Functional-Pragmatic, and it deals with those stories and practices in which digital management devices are used under Tajfel's conceptualization as "conformity" (Tajfel, 1982). Unlike device-lovers, users do not show conviction, but a certain resignation to use. Sometimes we observe an appropriation of the device to use it in ways and for purposes for which the device was not designed. To understand this repertoire, we use Scott's approach (2000). He explains that at least part of the consent practices is explained by the impossibility of elaborating direct opposition from subordinate people. This involves other types of subtle and covert strategies such as slow work or cynicism.

The type of digital devices in the functional-pragmatic repertoire is less specific than the devicelovers but always responds to the characteristic of being imposed by the institutional authorities. These are digital tools such as virtual classrooms, Moodle, Blackboard or online forms for institutional databases. In this repertoire, they tend to portray the devices as tools at the service of others, such as the institution, the students or administrative staff. But these tools do not bring personal benefit or correspond to the Faculty's interests or values. This points in the direction reported by Romero, Riquelme, and Halal (2019), where the implementation of DMDs in the student evaluation process is not perceived as fundamental to the learning processes. 
For example, a professor narrated the imposition by the provost of the use of the virtual classroom during the recent mobilizations in Chile:

Because of the rallies, we do not have face-to-face classes ... so we have to do virtual classes, but the students are still on strike and the institution is attentive to the virtual work we perform ... We have already been told that there may be consequences. What did I do? Upload readings and materials every other day. So I do not put pressure on the students to go back to classes (since they have the right to strike) and I do my responsibilities and record them on the platform, so I "work". (Psychology)

As the excerpt illustrates, the pressure exercised by the university towards the faculty to use digital tools is subtly confronted by the faculty (Scott, 2000). This is interesting since the virtual platform allows the academics to register who has worked, complies with the surveillance and facilitates the students to continue the strike. Similarly, actions such as pretending illiteracy of certain tools and thus delaying their implementation or slowing down their use were documented (example of this, the case of requests to upload information to certain platforms).

In this repertoire, we also found actions that Scott's denominate deception practices, where academics build unofficial or alternative uses subverting the purposes and uses designed and planned for digital devices. Example of this is the fragment below:

I am not attracted to online courses and that kind of stuff, I find them impersonal. However, the university forces me to maintain communication with the students out there, upload material, send messages. So what I give my password to my T/A and part of their tasks is to log in and take care of the virtual world of the course. (Pedagogy)

The actions framed in this repertoire are ambiguous and indicate a non-positioning regarding the technologies. This does not mean that they do not have an opinion. Rather, they tend to negatively value devices, but cannot evade it. So they undertake actions that show sub-optimal use. Under this repertoire, speakers tend to compromise in some respects, but seek to recover what they have compromised through other things (such as reduce the workload on the other hand).

To bureaucratize the process to account for issues so much, that you can account in another way..., it seemed Kafkaesque to me. Yes, everyone helps and of course, everyone collaborates in the task but (...) it's still wear and tear, it is exhausting because you have to be in many things at once. (Social work)

In the previous excerpt, we observed the recognition of the inefficiency and the lack of meaning of the management devices explicitly for university accreditation. A willingness to negotiate appears, where the faculty resigns themselves to accept the tasks of productivity and performance reporting, but on the other hand, they are trying to smooth the complex administrative process through collaborative work. This shift constitutes an important difference concerning the devices-lovers. In that sense, group work and collaborative work, break the logic of the new public management. Although the results expected by the institution are achieved, the premises of competitive and individual work that would mean improving the quality and performance of faculty are disarticulated. 


\section{c. Repertoire 3: Oppositionist-rejector}

The third repertoire includes all those stories that declare direct rejection, for various reasons, of the digital turn that the organization of university academic work has taken. Additionally, it brings together actions and strategies to hinder the implementation of these devices. We have gathered these stories under the name of oppositionist-rejector repertoire. This category explicitly positions itself against the implementation of digital management devices, declaring its explicit disapproval, assuming all the consequences that this may bring. In many cases, they are specific tools of each institution, as well as others beyond their universities but common to academic work. In this type of narration, the user perceives that the tool hinders their work, but unlike the functional-pragmatic ones, avoiding use is an option that does not matter the costs that exist for their jobs, nor are they considered significant. For these users at the least in their discourses, they are willing to face the consequences.

In the same way as Bartleby de Melville (1981), this group of faculty openly and explicitly argues that they would prefer not to use digital management devices, even if they continue to carry out their academic work correctly. As we will see, despite the diversity of nuances to oppose its use, there is common rhetoric of resistance and obstruction as a micropolitical practice against these devices. This category of faculty is sustained in practices and strategies of counter-discourses and counter-behaviors that suppose new ways of speaking and working subversively within the reasoning of accountability:

Eh, every day the responsibilities regarding accountability are increasing and increasing. This really is, it exhausts me because it is repetitive, ok. It is valid, but, they make the issue of asking for money more and more tedious and you have less and less freedom with the money, [...] A lot, take a lot of my time, then I say to myself "What a stupid system!", So, everything starts to get complicated and you start to see troubles and I say "you know what? I'm not going to apply" and I keep my small projects. (Chemistry)

In the previous fragment, we observe how a faculty relates her experience with the digital accountability system of research projects and grants. The bureaucracy and administrative controls reach limits where the lack of time and the feeling of being fed up are narrated. This professor explains her refusal to apply for funding that handles large amounts of money but moreover where accountability is complex and tedious. This rejection of an application to obtain grants with large management controls and that take up time for tasks such as teaching and research is part of the discourse of faculty who are oppositional to digital management devices, who prefer not to advance in the great milestones and academic merits, what It can prevent their academic career to growth, but thus preserve their time and mental health.

Well, for me, I made the decision a few years ago not to play the wicked system of the university. All this publication, the ISIs (index) ... I abandoned it because it doesn't make sense. And this is a clear positioning, huh? But it is also absurd to criticize all this and that I continue publishing in Q1, Q2 ... what do I know! Rankings, appreciation checks, and six-year terms stopped worrying me. And if one day they have to kick me out, well, so be it! (Odontology) 
Implicit in this argument, we also find directly inhibitory actions, where academics stop using the tool. Even on many occasions, they create a bad reputation on devices, inhibiting the use of their peers (in opposition to what device-lovers do).

The most frequent argument for rejecting digital tools in this type of repertoire is that the use of the devices means waste and squander of time for the user; without in return involving help. This is another clear difference with the device-lover repertoire. Another frequent argument for oppositionists-rejectors is that they do not have time to invest in learning how to use them or that they lack adequate training.

At some point, it occurred to the chair of my department that I have to use Zoom to teach. I opposed. I never understood it. I swear I didn't have time to call IT, ask to have it installed on my computer and then learn how to use it. No ... bye. It was too much. (Odontology)

In summary, this repertoire formulates the digital turn and the management tools housed there as a tendency for universities to control academic work and to withhold autonomy from faculty's work. Additionally, these types of devices are read as a work overload due to the excessive complexity or control of academic tasks. Associated with this repertoire, we find directly inhibiting actions, where academics stop using the tool. Even on many occasions, they complain about the tools, inhibiting the use of their peers. This type of action reveals a position of obstruction/impediment, and opposition/confrontational relationship with the device, of which the consequences do not matter anymore.

\section{Conclusions}

What do these results tell us about the response of academics to the digital turn in the management of higher education? Digital management devices in contemporary academia have brought about an important transformation in the ways in which faculty carry out their work. This article supported previous findings according to the existing literature, pointing that the response of academics to the digital turn of the academic management modes is paradoxical and heterogeneous. Additionally, this work has described in depth the heterogeneity and inconsistency of the academic response, using the interpretive repertoire analysis model, whose value lies in the sensitivity to address the variability of the discourse. Under this analytical framework, we conclude that there are at least three repertoires to interpret the experience with DMDs: device-lover, functional-pragmatic and oppositionist-rejector. Thus, these three repertoires converge to show that the successful implementation of management formulas based on digital devices necessarily goes through at least two conditions: 1) the user experience and their identity as a worker and 2) due to the relationship with the institutional context. that the tools in particular propose.

On the 1) experience-identity relationship, it appears clearly in the stories of the device lovers, since they will not use devices that go against them; or in the oppositionists, whose rejection narratives are only understood based on their track record in using DMDs. Therefore, to understand the success or failure of the implementation of DMDs, the user experience must be considered, like Henderson, Selwyn, Finger, and Aston (2015) affirmed that it happens with these devices in relation to students. Regarding the 2) relationship with the institutional context that the tools propose, we have shown how the particular repertoire is activated depending on the device and the relationship that it proposes to the faculty with their institution. Thus, for 
example, the relationship fails when it is one of control or accountability. However, when the device allows them to make their work visible, it is valued and accepted, which means success in the implementation of DMDs.

These results are reinforced by the findings of other studies at the international level. For example, when discussing the success in the implementation of DMDs, Van der Sluis, Reezigt and Borghans (2015) have studied how New Public Management policies are implemented in the Dutch Department of Education and conclude that although they are frequently accepted (such as the digital system of control of student attendance), it happens that the Department of Education itself directly rejects some initiatives when they do not align with their local and private interests. On the other hand, studies such as that of Sheard and Sharples (2015) show that educational management tools are better received when there is collaborative and exchange work, compared to those strategies where management devices are directly imposed or implemented without participation during the process. Likewise, an entire monograph from the International Journal of Educational Technology in Higher Education edited by Castañeda and Selwyn (2018), points to the importance of human processes and the criticism of hyperindividualization in the success of digital education. Taken together, all these results show that the perception and attribution of meanings that the actors involved (faculty) in the management process have is a central condition for the success of the implementation of the DMDs.

Our conclusion stresses out that the competitive and individualistic essence of the new public management (and in general, of the neoliberal model), focused on individual characteristics, would be a failure for the optimal implementation of the DMDs. The explanation of the rejection of DMDs that most academics tend to be "digital immigrants" or digital illiterates, would be insufficient. Faculty tend to use and overuse the tools that enhance their academic career and their interests, and not necessarily those of the institution.

In this sense, within institutions that have implemented these management models, the competitive spirit is detrimental to the development of academic communities (Gill, 2009). Taking into account our results, we can say that it fosters functional pragmatic repertoires where unexpected purposes and modes of use appear while being re-appropriate to the purposes of the academics themselves and not of the DMDs or the institution.

Similarly, Roberts and Col. (2007) postulate that there would be three general factors that influence the acceptance of DMDs by faculty, these are 1) social factors (peers' attitudes and behaviors, friendship networks...), 2) organizational factors (administration, infrastructure provided by the institution...), and 3) individual factors (learning new skills, achieve personal goals...). Therefore, the cultural and relational aspects, and specifically, the feeling of autonomy and control, are decisive when designing and predicting the success of DMDs. Our exploratory hypothesis is that academics have a deep-rooted culture of autonomy and discipline, which makes it difficult for them to work in highly controlled work contexts or that detracts from autonomy as this would be central to academics' professional identity. Therefore, its design cannot be deaf to the experience, ideology and local grammar of the identity position of the faculty.

This argument aligns with other authors who are also studying the implications of DMDs in academia. For example, Bristow, Robinson, and Ratle (2017) affirm that the practices of resistance against the incoming of the neoliberal system to the academy are complex and full of nuances and contradictions. These practices range from specific strategic alliances to the paradoxical defense of neoliberal processes (such as being highly cited, to being in a job position that allows them to break publicly with them). For the implementation of the DMDs to be a success, it must be accompanied by working on the relationships established between the faculty 
and the institution. This implementation cannot be isolated from the identity or cultural aspects of the institution in which they are implemented (and therefore, from their academics). If the implementation occurs as part of a series of measures that increase management control, the devices will be rejected as they are perceived as a control tool that imposes a form of a vertical and asymmetric relationship on work processes.

Therefore, based on the results of this research and its intersection with international literature, it is recommended that, when implementing digital management devices in higher education, the institution should: 1) Have binding and direct participation of faculty. Even when this point, which may seem naive and obvious in the studies of digital education, is not so much in terms of management and implementation of public accountability and neoliberal policies, where bottomup participation in a binding manner is scarce and is reduces to spaces that are not truly open beyond managers or politicians; 2) That this participation does not consist of a mere survey or suggestion mailbox, but rather gathers the meanings and experience that DMDs mean to them; 3) That a genuine engagement and commitment with faculty is generated, as this increases the chances of success in the design and implementation of DMDs; and 4) That IT, engineers and programmers work together with the people who have more experience in management tasks in higher education.

\section{Acknowledgments}

This research was supported by FONDECYT Regular 1180129, FONDECYT Iniciación 11190195, PIA ANID CIE 160009 and Centro Núcleo Milenio Autoridad y Asimetrías de Poder.

\section{References}

Anderson, G. (2008). Mapping Academic Resistance in the managerial University. Organization, 15(2), 251270.

Bernasconi, A. (2015). La Educación Superior de Chile: Transformación, desarrollo y crisis. Santiago: Ediciones Universidad Católica de Chile.

Billig, M., Condor, S. Edwards, D. Gane, M. Middleton, D. \& Radley, A. (1988). Ideological Dilemmas. London: Sage.

Bristow, A. Robinson, S. \& Ratle, O. (2017). Being an Early-Career CMS Academic in the Context of Insecurity and "Excellence": The Dialectics of Resistance and Compliance. Organization Studies, 38(9), 1185-1207.

Brunner, J. (2008). Educación superior en Chile: instituciones, mercados y políticas gubernamentales. Leiden: Leiden.

Castañeda, L., \& Selwyn, N. (2018). More than tools? Making sense of the ongoing digitizations of higher education. International Journal of Educational Technology in Higher Education, 15(22). DOI:10.1186/s41239-018-0109-y

Chanphirun, S. \& Van Der Sijde, P. (2014). Understanding the concept of the entrepreneurial university from the perspective of higher education models. Higher Education, 68(6), 891-908.

Chesley, N. (2014). Information and communication technology use, work intensification and employee strain and distress. Work, Employment and Society, 28, 589-610. doi:10.1177/ 0950017013500112 
Claartje L. Zoonen, W. \& Fonner, K. (2016) The practical paradox of technology: The influence of communication technology use on employee burnout and engagement. Communication Monographs, 83(2), 239-263, DOI: 10.1080/03637751.2015.1133920

Daanen, H. \& Facer, K. (2007). Opening Education: 2020 and beyond Future scenarios for education in the age of new technologies. Available in: www.futurelab.org.uk/openingeducation

Davenport, T. H. \& Prusak, L. (1998). Working Knowledge: How Organizations Manage What They Know. Cambridge, MA: Harvard Business School Press.

Denzin N. \& Lincoln Y. (1994). Handbook of qualitative research. Thousand Oaks, CA: Sage.

Edwards, D. \& Potter, J. (1992). Discoursive Psychology. London: Sage.

Gill, R. (2009). Breaking the silence. The hidden injuries of neo-liberal academia. In R. Flood, \& R. Gill, Secrecy and silence in the research process: Feminist Reflections. London: Routledge.

Hall, D. Gunter, H. Serpieri, R. (2015). Educational reform and modernization in Europe: the role of national contexts in mediating the new public management. European Educational Research Journal, 14(6), 487-507.

Han, B. (2014). Psicopolítica. Barcelona: Herder.

Henderson, M. Selwyn, N. Finger, G. \& Aston, R. (2015). Students' everyday engagement with digital technology in university: exploring patterns of use and 'usefulness'. Journal of Higher Education Policy and Management, 37(3), 308-319. DOI: 10.1080/1360080X.2015.1034424

Holstein, J. \& Gubrium, J. (1995). The Active Interview. London: Sage.

Lundvall, B. (2002). The University in the Learning Economy. DRUID Working Paper No 02-06. Available in: http://www.druid.dk/wp/pdf_files/02-06.pdf

Mason, R. \& Rennie, F. (2008). E-learning and Social Networking Handbook. New York: Routledge.

Melville, H. (1981). Bartleby. México, D.F: Premià Editora.

Moore, P., \& Robinson, A. (2015). The Quantified Self: What counts in the neoliberal workplace. New Media \& Society.

Naciones Unidas. (2019). Desarrollo Digital: Oportunidades y Desafíos. Disponible en: https://unctad.org/meetings/es/SessionalDocuments/tdb66_d5_es.pdf

Organización Para La Cooperación Y El Desarrollo Económico. (2002). Confianza en el gobierno. Medidas para fortalecer el marco ético en los países de la OCDE. Paris: OCDE.

Organización Para La Cooperación Y El Desarrollo Económico. (2004). Revisión de Políticas Nacionales de Educación. Paris: OCDE.

OCDE. (2009). La educación superior en Chile: Revisión de políticas nacionales de educación. Santiago: Ministerio de Educación.

Perlow, L., \& Weeks, J. (2002). Who's helping whom? Layers of culture and workplace behavior. Journal of Organizational Behavior, 23, 345-361. doi:10.1002/job.150

Potter, J. \& Wetherell, M. (1987). Discourse and Social Psychology. London: Sage.

Richtel, M. (2011). As doctors use more devices, potential for distraction grows. The New York Times, 14 December, http://www.nytimes.com/2011/12/15/health/as-doctors-use-moredevices-potential-fordistraction-grows.html?pagewanted=all

Romero, R. Riquelme, I. Halal, C. (2019). Barriers in Teacher Perception about the Use of Technology for Evaluation in Higher Education. Digital Education Review, 35, 170-185.

Scott, J. (2000). Los dominados y el Arte de la Resistencia. Mexico: Era. 
Selwyn, N. Nemorin, S. \& Johnson, N. (2016). High-tech, hard work: an investigation of teachers' work in the Digital Age. Learning, Media and Technology, 42(4), 390-405. DOI: 10.1080/17439884.2016.1252770

Sheard, M. \& Sharples, J. (2016). School Leader's Engagement with the Concept of Evidence-based Practice as a Management Tool for School Improvement. Educational Management Administration \& Leadership, 44(4), 668-687.

Slaughter, S. \& Leslie, L. (2001). Expanding and Elaborating the Concept of Academic Capitalism. Organization, 2(8), 154-161.

Slaugther, S., \& Leslie, L. (1997). Academic Capitalism: Politics, Policies \& The Enterpreneurial University. Baltimore: The Johns Hopkins University Press.

Southerton, D. (2007). Time pressure, technology and gender: the conditioning of temporal experiences in the UK. Equal Opportunities International, 26(2): 113-28.

Tajfel, H. (1982). Social psychology of intergroup relations. Annual Review of Psychology, 33, 1-39.

Thomas, R. \& Davies, A. (2005). Theorizing the micro-politics of resistance: New public management and managerial identities in the UK public services. Organization Studies, 26, 683-706.

Thompson, D. (2011). The case for banning email at work. The Atlantic, 1 December, http://www. theatlantic.com/business/archive/2011/12/the-case-for-banning-email-at-work/249252/\#

Van Der Merwe, H. \& Wetherell, M. (2019). The emotional psychologist: A qualitative investigation of norms, dilemmas, and contradictions in accounts of practice. Journal of Community \& Applied Social Psychology, 1-19. https://doi.org/10.1002/casp.2439

Van Der Sluis, M. Reezigt, G. J. \& Borghans, L. (2017). Implementing New Public Management in Educational Policy. Educational Policy, 31(3), 303-329. https://doi.org/10.1177/0895904815598393

Vanderlinde, R., Van Braak, J. \& Tondeur, J. (2010), Using an online tool to support school-based ICT policy planning in primary education. Journal of Computer Assisted Learning, 26: 434-447. doi:10.1111/j.1365-2729.2010.00358.x

Wajcman J. \& Rose E. (2011) Constant connectivity: rethinking interruptions at work. Organization Studies, 32(7): 941-61.

Watty, K. McKay, J. \& Ngo, L. (2016). Innovators or inhibitors? Accounting faculty resistance to new educational technologies in higher education. Journal of Accounting Education, 36, 1-15. doi: 10.1016/j.jaccedu.2016.03.003

Wittmann, E. (2008). Align, don't necessarily follow. Educational Management Administration \& Leadership, $36,33-54$

World Bank. (2005). Education Sector Strategy Update. Washington, D.C.: World Bank.

World Bank. (2011). Learning For All: Investing In People's Knowledge And Skills To Promote Development. World Bank Group Education Sector Strategy 2020. Washington, D.C.: World Bank. 